PÉRIODIQUES. Zeitschr. f. rom. Phil. XVI 3-4; Rom. Forschungen IV, V; Rev. de philol. frç. et prov. VI ; Bull. de la Soc. d. anc. text. 1892 ; Propugn. 1891, 1892.

\title{
CHRONIQUE.
}

A. Toblek.

\section{Nachtrag zu Zs. XVII 282.}

Zwei weitere Handschriften mit den Quinze joyes und den Sept requestes werden von $\mathrm{Karl} \mathrm{Hiersemann}$ in Leipzig, Königsstrafse 2, zum Verkauf angeboten, Verzeichnis 112 N. 864 und 865.

SUCHIER. 